\title{
Bullying victimization, physical inactivity and sedentary behavior among children and adolescents: a meta-analysis
}

Antonio García-Hermoso ${ }^{1,2^{*}}$ (D), Ignacio Hormazabal-Aguayo ${ }^{2}$, Xavier Oriol-Granado ${ }^{3}$, Omar Fernández-Vergara ${ }^{2}$ and Borja del Pozo Cruz ${ }^{4}$

\begin{abstract}
Background: Physical activity and sedentary behavior are related with psycho-social variables among youth, however its relationship with bullying victimization is unclear. The aim of the study was to clarify the associations between physical activity and sedentary behaviors with bullying victimization among children and adolescents.

Methods: Two independent authors searched in four databases. The studies were selected/included only if participants were children and/or adolescents and the relationship between physical activity and/or sedentary behavior with bullying victimization was reported. Random-effects meta-analyses were used.

Results: A total of 18 cross-sectional studies (including 386,740 children and adolescents, 51.8\% females) were reviewed. Our study found that not meeting the physical activity guidelines (Odds Ratio $[O R]=1.14,95 \%$ confidence interval [Cl], 1.04 to 1.23) and excessive sedentary behavior (i.e., $2 \mathrm{~h}$ per day or more of screen time) $(\mathrm{OR}=1.21,95 \% \mathrm{Cl}, 1.14$ to 1.28$)$ were associated with 14 and $21 \%$ higher bullying victimization, respectively. Consistent associations were also found when we analyzed specific forms of bullying for sedentary behavior, including traditional and cyberbullying.

Conclusions: The present study establishes the first quantitative framework for understanding the influence of physical activity and sedentary behavior on bullying victimization, and lays the groundwork for future studies and interventions aimed to its promotion.
\end{abstract}

Trial registration: CRD42018099388.

Keywords: Physical exercise, Sitting time, Screen time, traditional bullying, Cyberbullying

\section{Introduction}

Bullying victimization denotes to the process by which an individual is repeatedly and over time exposed to intentional harmful or negative actions by their counterparts [1]. Bullying can occur in different environments,

\footnotetext{
* Correspondence: antonio.garciah@unavarra.es

${ }^{1}$ Navarrabiomed, Complejo Hospitalario de Navarra (CHN)-Universidad

Pública de Navarra (UPNA), IdiSNA, Calle de Irunlarrea, 3, Postal Code: 31008 Pamplona, Navarra, Spain

${ }^{2}$ Laboratorio de Ciencias de la Actividad Física, el Deporte y la Salud, Universidad de Santiago de Chile, USACH, Santiago, Chile

Full list of author information is available at the end of the article
}

including but not limited to workplace, community settings, schools and home [2]. Bullying victimization is prevalent across countries worldwide, reaching prevalence rates up to $35 \%$ for traditional bullying and $15 \%$ for cyberbullying [3]. According to the Centers for Disease Control and Prevention (CDC), bullied youths frequently report high levels of poor school performance, sleep difficulties, loneliness, anxiety, depression [4] and are more likely to commit suicide [5].

Physical inactivity among youth predicts a wide range of health problems that are detrimental to well-being 
[6]. International guidelines from organizations such as the US Department of Health and Human Services [7] and the World Health Organization [8] recommend that children and adolescents should have at least $1 \mathrm{~h}$ or more per day of moderate-to-vigorous physical activity. There is evidence that suggests that, when a child or adolescent spends a large amount of time in a sedentary behavior it relates to a poorer health outcome, being somewhat stronger for television (TV) viewing and other screen behaviors than for total sedentary time [9]. In recent years, the rapid adoption of digital media has displaced the consumption of legacy media such as reading a book or a magazine [10]. The American Academy of Pediatrics recommends no more than $2 \mathrm{~h}$ per day of any screen-based activity [11]. In this regard, there is evidence that has shown that spending an excessive amount of time in screen-based activities can have a direct relationship to the development of anti-social behavior and aggression [12] and more negative feelings [13]. Therefore, it is important to understand how bullying status relates to whether youth meet or do not meet the physical activity and sedentary behavior recommendations. Therefore, the purpose of this study was to provide a quantitative analysis on the associations of physical activity and sedentary behavior on bullying victimization among children and adolescents.

\section{Methods}

A systematic review and meta-analysis was conducted according to the Preferred Reporting Items for Systematic Reviews and Meta-Analyses (PRISMA) [14]. The review was registered in PROSPERO (registration number: CRD42018099388).

\section{Data sources and searches}

Two independent authors (IH-A \& AG-H) searched PubMed, EMBASE, ERIC and PsycARTICLES, from database inception to May 20th, 2020. Studies were identified by using all possible combinations of the following groups of search terms: (a) "bull" OR "victim" OR "peer relation"; (b) "physical activity" OR "exercise"; and (c) "sedentary" OR "screen time" OR "television" OR "video game" OR "computer". The complete search strategy is shown in Additional file. Only English articles were included. In addition, the reference lists and related links of retrieved articles were examined to detect studies potentially eligible for inclusion.

\section{Study selection}

Studies needed to meet the following criteria: (a) subjects: children and adolescents aged 6 up to 18 years old; (b) type of study: cross-sectional and prospective cohort studies; (c) exposure: objective or subjective measured of physical activity and/or sedentary behavior; and (d) outcomes: bullying victimization as dependent variable. The first and second author (IH-A \& AG-H) independently assessed the electronic search results. Reasons for exclusion of identified studies were recorded.

\section{Data extraction}

The following information was extracted from the studies meeting the selection criteria: country of study, participants (e.g., sex, age), type of bullying (i.e., traditional or cyberbullying), physical activity and sedentary behavior assessment of each study and study results.

\section{Risk of bias in individual studies}

The risk of bias was assessed by The Quality Assessment Tool for Observational Cohort and Cross-sectional Studies [15]. This methodological tool is composed of fourteen items rated as "yes", "no" or "not reported".

\section{Data synthesis and analysis}

Odds Ratio (OR) and 95\% confidence interval (CI) were pooled using random effect models (DerSimonian and Laird) [16] to account for anticipated between-study heterogeneity. This heterogeneity (Cochran's Q-statistic) was estimated using $\mathrm{I}^{2}$, considering $\mathrm{I}^{2}$ values of $<25 \%$, $25-50$, and $>50 \%$ as small, medium, and large amounts of heterogeneity respectively [17].

Publication bias was determined by visual examination of funnel plots (only used for overall adiposity). Also, small-study effects bias was assessed using Egger's test [18].

Finally, subgroup moderator analyses were conducted to determine whether results differed according to sex, specifics form of bullying and type of sedentary behavior.

All analyses were carried out using the STATA 13.1 Software (Stata Corporation LP, College Station, TX, USA).

\section{Results \\ Literature search}

The electronic search strategy identified 521 studies and, after screening for duplicates, 43 full-text studies were assessed for inclusion after checking titles and abstracts. Finally, 18 studies met the inclusion criteria and were included in the systematic review and 14 in the metaanalysis. The flow diagram showing the number of articles excluded at each stage of the systematic review and meta-analysis is shown in Fig. 1.

\section{Study characteristics}

Table 1 summarizes the characteristics of the 18 included studies. All of them were cross-sectional observational studies, and were published from 2007 to 2020 . The studies included 386,740 children and adolescents. 


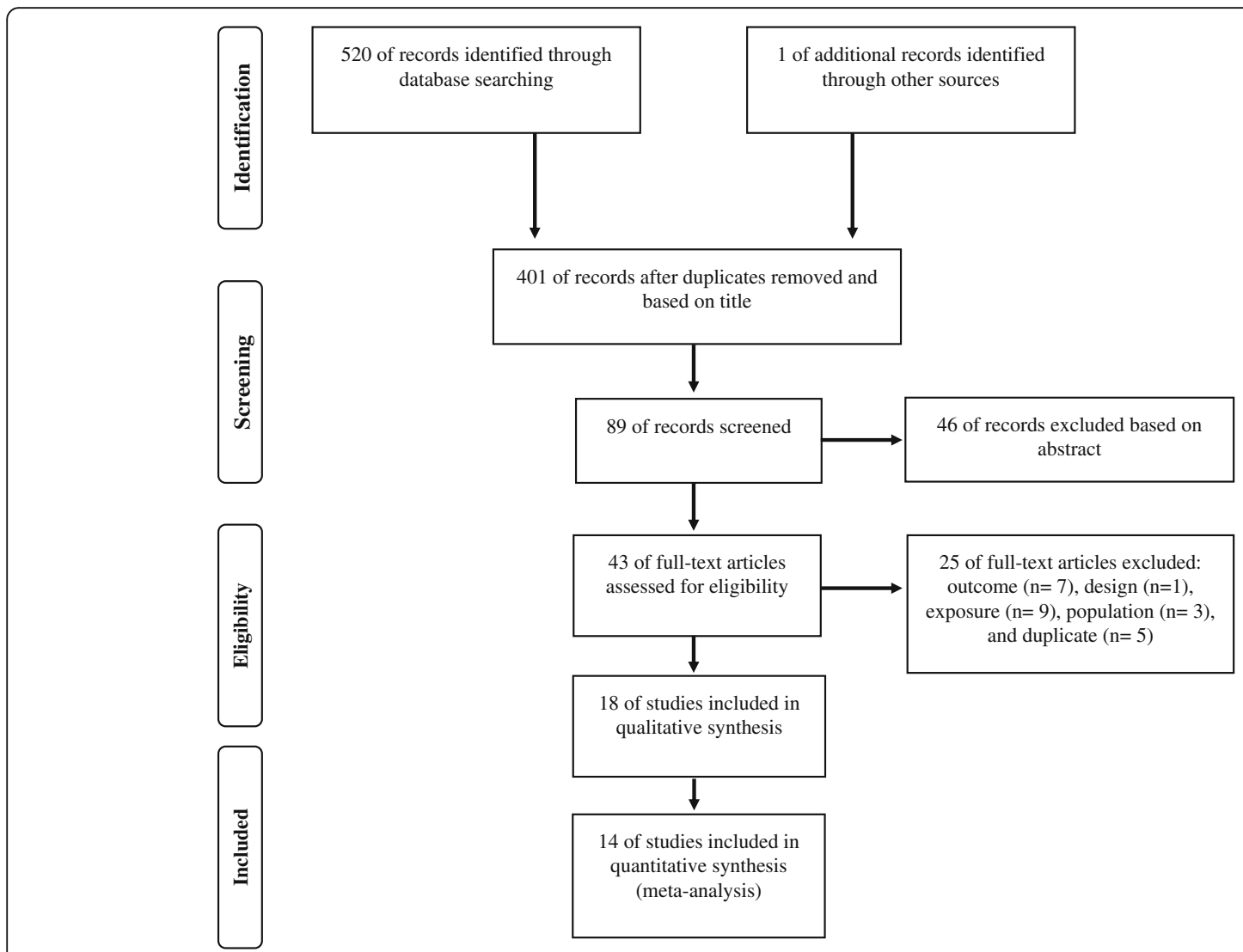

Fig. 1 Flow chart for identification of trials for inclusion in the meta-analysis

Sample sizes ranged from 54 [22] to 237,121 participants [19]. All studies included males and females $(51.8 \%$ females). Twelve studies included only adolescents (12-18 years old) $[19,20,24,27-29,31,32,34-37]$ and the remaining studies included both children and adolescents.

All included studies used a self-reported questionnaire to assess physical activity and sedentary behavior, except two which assessed physical activity with accelerometers $[22,36]$. Most studies defined physical inactivity as less than 60 min of moderate to vigorous-intensity physical activity per day on at least 7 days per week $[19,21,23,24$, 26, 34]. Regarding sedentary behavior, studies analyzed this behavior as hours per day of television, computer/ video game, and screen time use or sitting time; also, most studies defined excessive sedentary behavior as at least $3 \mathrm{~h}$ average per school day.

School bullying victimization was assessed using a questionnaire. While a limited number of the included studies used a validated bullying questionnaire [20, 22, $25,29,31,32,35]$, the majority of the studies used a single item to assess bullying (e.g., "During the past 12 months, have you ever been bullied on school property?"). Moreover, most studies focused on traditional bullying victimization (i.e. referring to physical abuse behaviors, verbal or weight-teasing, psychological abuse and social exclusion) and five in cyberbullying (i.e. texting, emails, social network sites) [22, 26, 30, 33, 34].

\section{Risk of bias within studies}

All 18 studies met at least 6 criteria and were considered to have moderate methodological quality. The average score was 7.5/14.0 (Table 1 and Additional file 1).

\section{Meta-analysis of the association between physical activity and bullying victimization}

Overall, there was evidence that not meeting the current physical activity guidelines was associated with higher bullying victimization $(\mathrm{OR}=1.14,95 \% \mathrm{CI}, 1.04-1.23$; $p<0.001 ; \mathrm{I}^{2}=73.8 \%$ ) (Fig. 2).

According to the type of bullying, not meeting the physical activity guidelines was also associated with higher traditional bullying ( $\mathrm{OR}=1.1695 \% \mathrm{CI}, 1.05-1.27$; $p<0.002 ; \mathrm{I}^{2}=68.8 \%$ ) (Fig. 2). Finally, according to sex, not meeting the physical activity guidelines was not associated with bullying victimization in females $(\mathrm{OR}=$ $\left.1.08,95 \% \mathrm{CI}, 0-91-1.28 ; p=0.395 ; \mathrm{I}^{2}=0 \%\right)$ or males $\left(\mathrm{OR}=1.15,95 \%\right.$ CI, $\left.0.96-1.38 ; p=0.126 ; \mathrm{I}^{2}=0 \%\right)$. 


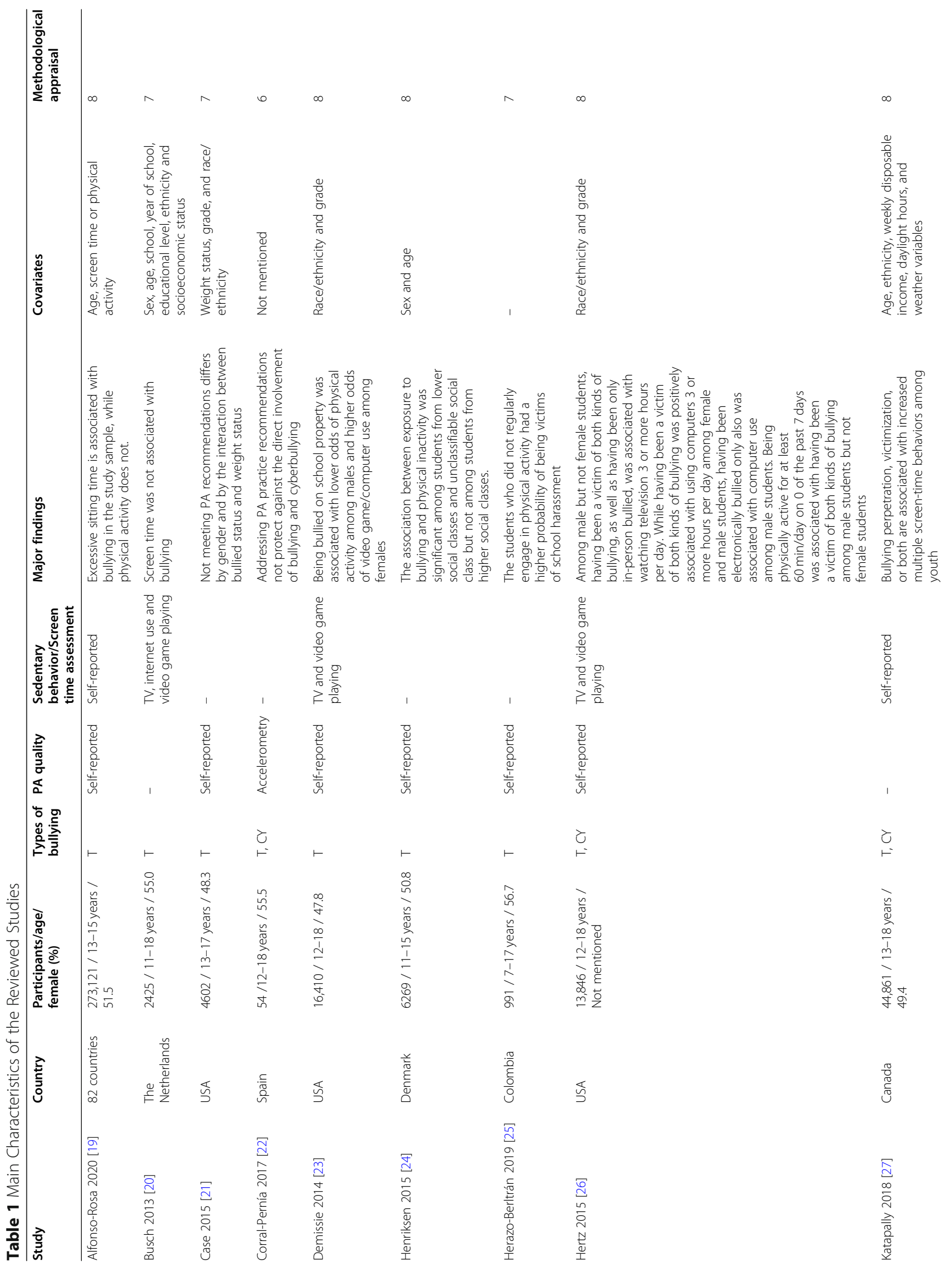




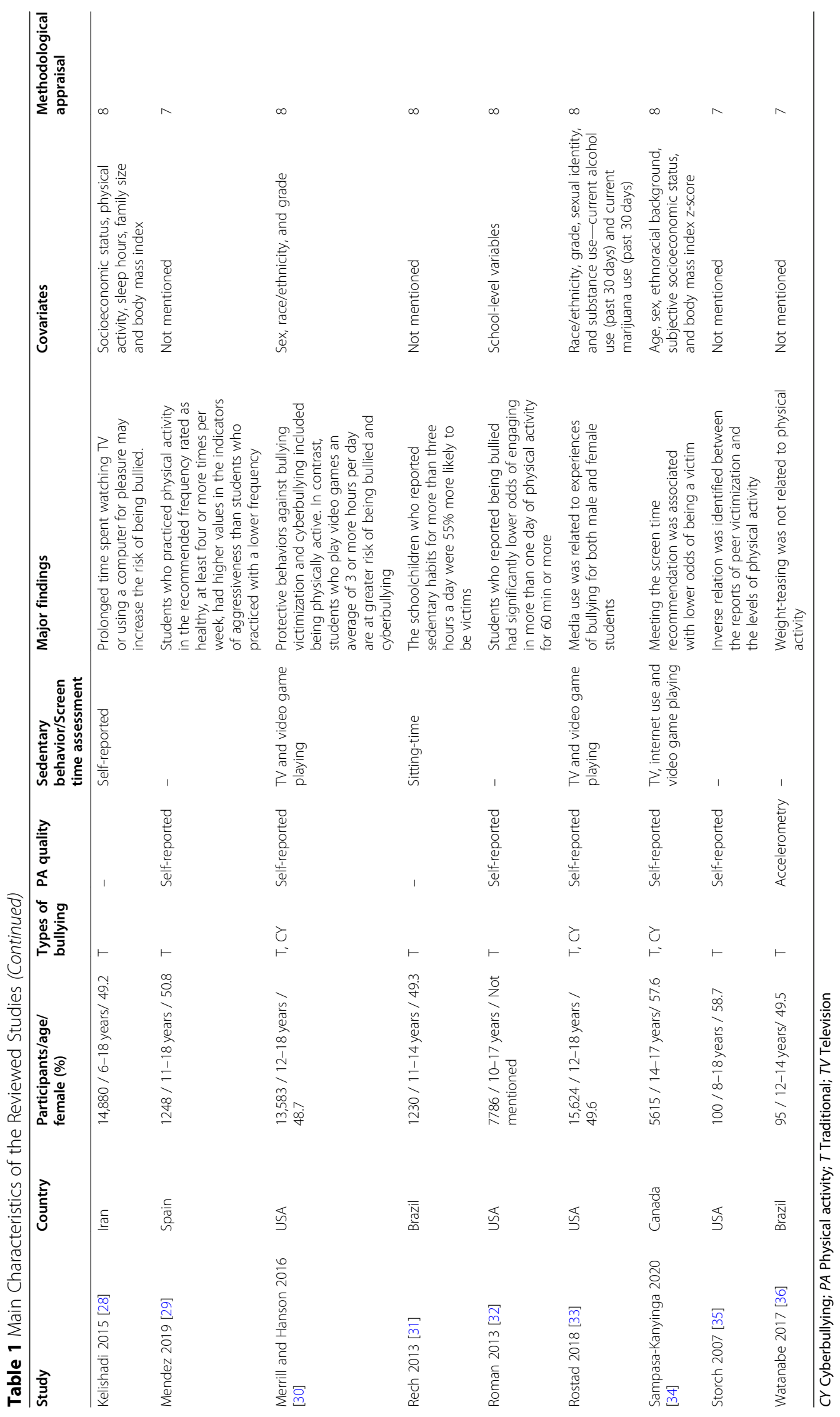




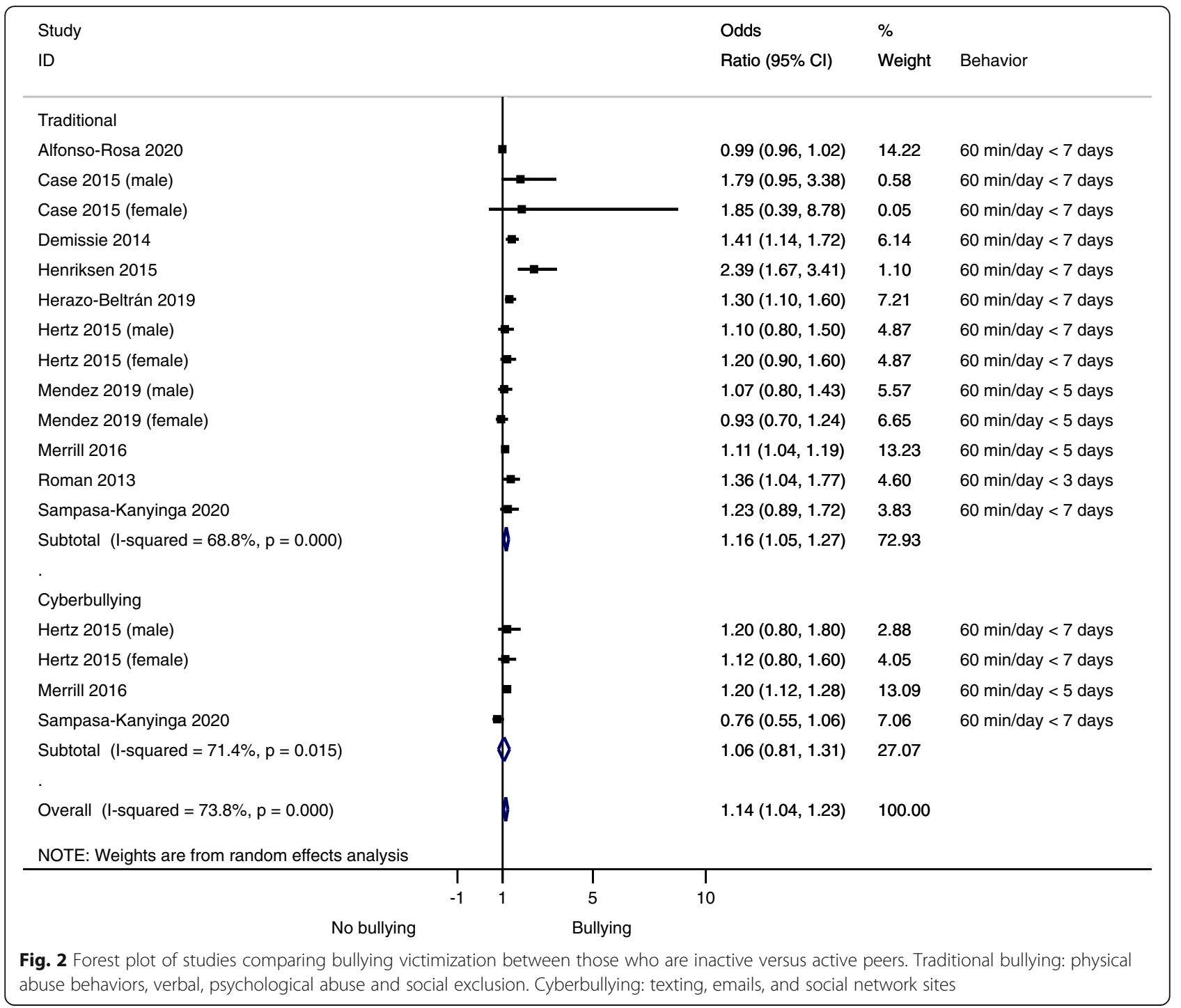

\section{Meta-analysis of the association between sedentary behavior and bullying victimization}

Excessive sedentary behavior was associated with higher bullying $\left(\mathrm{OR}=1.21,95 \% \mathrm{CI}, 1.14-1.28 ; p<0.001 ; \mathrm{I}^{2}=\right.$ $89.6 \%)$, cyberbullying ( $\mathrm{OR}=1.20,95 \% \mathrm{CI}, 1.06-1.33 ; p<$ $\left.0.001 ; \mathrm{I}^{2}=86.9 \%\right)$, and traditional bullying ( $\mathrm{OR}=1.22,95 \%$ CI, 1.13-1.30; $p<0.001 ; \mathrm{I}^{2}=90.1 \%$ ) (Fig. 3). Results also showed associations in both sexes (males, OR $=1.25,95 \%$ CI, 1.14-1.37; $p<0.001 ; \mathrm{I}^{2}=29.06 \%$; females, $\mathrm{OR}=1.10$, 95\% CI, 1.03-1.18; $\left.p=0.006 ; \mathrm{I}^{2}=23.46 \%\right)$. According to type of sedentary behavior, watching TV $(\mathrm{OR}=1.08,95 \%$ CI, 1.01-1.14; $\left.p=0.016 ; \mathrm{I}^{2}=51.16 \%\right)$, computer use (OR = $1.21,95 \%$ CI, 1.04-1.42; $\left.p=0.014 ; \mathrm{I}^{2}=50.32 \%\right)$, leisure time spent playing video games $(\mathrm{OR}=1.27,95 \% \mathrm{CI}, 1.20$ 1.35; $\left.p<0.001 ; \mathrm{I}^{2}=0 \%\right)$ or total sitting time $(\mathrm{OR}=1.38$, 95\% CI, 1.34-1.42; $\left.p<0.001 ; \mathrm{I}^{2}=0 \%\right)$ were associated with higher bullying victimization.

\section{Sensitivity analysis and publication bias}

When the impact of individual studies was examined by removing studies from the analysis one at a time, we observed that the pooled results estimate remained consistent.

Both funnel plot asymmetry (Additional file 1) and Egger test showed no significant publication bias for physical activity (bias $=1.99 ; 95 \% \mathrm{CI}, 0.38$ to $3.60 ; p=0.018$ ) and sedentary behavior (bias $=-1.14 ; 95 \% \mathrm{CI},-2.89$ to $0.61 ; p=0.194$ ), indicating no evidence of publication bias.

\section{Discussion}

To the best of our knowledge, the current review is the first to assess the associations of physical activity and sedentary behavior with bullying victimization among children and adolescents. Our study found that not meeting the physical activity guidelines and excessive 
an increased risk of being bullied due to factors such as poor motor skills [42], physical fitness [43], and low selfconfidence to engage in physical activities.

\section{Sedentary behavior and bullying victimization}

Among children and adolescents, television viewing and other screen-based forms of entertainment are the most prevalent leisure-time sedentary behaviors [44]. Recent studies of electronic media use and TV viewing have concluded that this type of sedentary behavior (i.e. screen-based) is associated with lower pro-social behavior, self-esteem [45] and subjective well-being [13] in children and adolescents. In this regard, our metaanalysis reveals that excessive sedentary behavior was related with $21 \%$ higher bullying victimization, and found that this relationship is consistent across both, traditional (22\%) and cyberbullying (20\%). Increased screenbased activities use may diminish experiences of personal interaction that helps youth develop interpersonal relationships and academic skills, pro-social behavior and conflict resolution [46], which could place youths at risk of multiple forms of victimization in relationships with dating partners, friends, and peers [47]. Furthermore, studies suggest that friendships can function as a protective factor against the negative adjustment often experienced by bullied youth [47]. In contrast, screen-based activities favor loneliness [12]. For example, more screen time such as play video game seems to compromise youth development of interpersonal skills hence making them vulnerable to all forms of bullying [33]. Regarding electronic bullying victimization, both male and female youths could be exposed to cyberbullying through social media consuming during computer use [33].

Socio-economic factors seem to be related with bullying prevalence. For example, it has been suggested that adolescents from lower social classes are more exposed to victimization compared to adolescents from high socio-economic status [24]. In this regard, it is interesting to highlight findings from Alfonso-Rosa et al. [19] who indicated that the odds of being bullied were lower for adolescents who exceeded sitting guidelines in high Human Development Index countries compared to those in low Human Development Index countries.

\section{Limitations}

There are several limitations to this meta-analysis that should be acknowledged. First, our results are based on cross-sectional studies and so causality cannot be inferred. Reverse causality could also be true, i.e., youths bullied could be less prone to follow healthy lifestyle habits $[48,49]$. Second, all of the studies except two $[22,36]$ did not include a rigorous physical activity and sedentary behavior assessment. Therefore, self-reported questionnaires could potentially be subject to socially desirable reporting bias. Third, only five studies used validated bullying questionnaires [20, 22, 29, $31,32,35]$. In this sense, outcome measures for bullying are not standardized across the studies performed in different countries with likely variable cultural norms. Also, studies used different time frames to determine bullying (i.e. past month, past couple of months, current or past school year). Thus, the discrepancy in definitions might explain the heterogeneity of our results. Finally, physical activity and sedentary behavior were dichotomized, therefore, the current study cannot determine if the association varies across different levels of physical activity or sedentary intensity and participation.

\section{Conclusions}

This meta-analysis establishes the first quantitative framework for understanding the influence of physical activity on bullying victimization, showing that not meeting the physical activity guidelines and excessive sedentary behavior are associated with higher bullying victimization. Furthermore, it lays the groundwork for future studies and interventions aimed to bullying victimization prevention through promoting physical activity and reducing sedentary behaviors.

\section{Supplementary information}

Supplementary information accompanies this paper at https://doi.org/10. 1186/s12966-020-01016-4.

\section{Additional file 1. Table. Items of Quality Assessment Tool for} Observational Cohort and Cross-sectional studies. Figure. Funnel plot for physical activity on bullying victimization, with 95\% confidence limits. Figure. Funnel plot for sedentary behavior on bullying victimization, with 95\% confidence limits.

\section{Abbreviations}

CDC: Centers for disease control and prevention; Cl: Confidence interval; TV: Television; OR: Odds ratio

Acknowledgements

AGH is a Miguel Servet Fellow (Instituto de Salud Carlos III -FSE, CP18/0150).

\section{Authors' contributions}

Dr. García-Hermoso and Mr. Hormázabal-Aguayo conceptualized and designed the study, drafted the initial manuscript, and reviewed and revised the manuscript. Drs del Pozo-Cruz and Oriol-Granado designed the data collection instruments, collected data, carried out the initial analyses, and reviewed and revised the manuscript. Mr. Omar Fernández-Vergara conceptualized and designed the study, coordinated and supervised data collection, and critically reviewed the manuscript for important intellectual content. All authors approved the final manuscript as submitted and agree to be accountable for all aspects of the work.

\section{Funding}

None.

Availability of data and materials

The datasets used and/or analyzed during the current study are available from the corresponding author on reasonable request.

Ethics approval and consent to participate Not applicable. 


\section{Consent for publication}

Not applicable.

\section{Competing interests}

The authors declare that they have no competing interests.

\section{Author details}

'Navarrabiomed, Complejo Hospitalario de Navarra (CHN)-Universidad Pública de Navarra (UPNA), IdiSNA, Calle de Irunlarrea, 3, Postal Code: 31008 Pamplona, Navarra, Spain. ${ }^{2}$ Laboratorio de Ciencias de la Actividad Física, el Deporte y la Salud, Universidad de Santiago de Chile, USACH, Santiago, Chile. ${ }^{3}$ Facultad de Educación, Universidad Andres Bello, Santiago, Chile. ${ }^{4}$ Institute for Positive Psychology \& Education, Australian Catholic University, Sydney, Australia.

\section{Received: 23 May 2020 Accepted: 2 September 2020}

Published online: 11 September 2020

\section{References}

1. Hamburger ME, Basile KC, Vivolo AM. Measuring bullying victimization, perpetration, and bystander experiences: a compendium of assessment tools. Atlanta, GA: Centers for Disease Control and Prevention, National Center for Injury and Control; 2011.

2. Kupferman-Meik FE, Burris-Warmoth P, Rapaport S, Roychoudhury K, Javier RA. Bullying in children and adolescents: a healthcare perspective. J Soc Distress Homeless. 2013;22:94-118. https://doi.org/10.1179/1053078913Z. 0000000006

3. Modecki KL, Minchin J, Harbaugh AG, Guerra NG, Runions KC. Bullying prevalence across contexts: a meta-analysis measuring cyber and traditional bullying. J Adolesc Health. 2014:55:602-11.

4. Centers for Disease Control and Prevention. (2011). Understanding bullying fact sheet. Retrieved from http://www.cdc.gov/NiolencePrevention/pdf/ Bullying_Factsheet-a.pdf.

5. Holt M, Vivolo-Kantor A, Polanin J, Holland KM, DeGue S, Matjasko JL, Wolfe M, Reid G. Bullying and suicidal ideation and behaviors: a meta-analysis. Pediatrics. 2015;135(2):e496-509. https://doi.org/10.1542/peds.2014-1864.

6. Booth FW, Roberts CK, Thyfault JP, Ruegsegger GN, Toedebusch RG. Role of inactivity in chronic diseases: evolutionary insight and pathophysiological mechanisms. Physiol Rev. 2017:97:1351-402.

7. Piercy KL, Troiano RP, Ballard RM, Carlson SA, Fulton JE, Galuska DA, et al. The physical activity guidelines for Americans. JAMA. 2018;320:2020. https:// doi.org/10.1001/jama.2018.14854

8. World Health Organization. Global recommendations on physical activity for health. 2010. https://apps.who.int/iris/bitstream/handle/10665/44399/ 9789245599975_chi.pdf. Accessed 22 May 2020.

9. Saunders TJ, Vallance JK. Screen time and health indicators among children and youth: current evidence, limitations and future directions. Appl Health Econ Health Policy. 2017;15:323-31.

10. Twenge JM, Martin GN, Spitzberg BH. Trends in U.S. adolescents' media use, 1976-2016: the rise of digital media, the decline of TV, and the (near) demise of print. Psychol Pop Media Cult. 2018;12:271-83.

11. Bar-On ME, Broughton DD, Buttross S, Corrigan S, Gedissman A, González De Rivas MR, et al. American academy of pediatrics: children, adolescents, and television. Pediatrics. 2001;107:423-6.

12. Robertson LA, McAnally HM, Hancox RJ. Childhood and adolescent television viewing and antisocial behavior in early adulthood. Pediatrics. 2013;131:439-46.

13. García-Hermoso A, Hormazábal-Aguayo I, Fernández-Vergara O, Olivares PRO-GX. Physical activity, screen time and subjective well-being among children. Int J Clin Heal Psychol. 2020;20(2):126-34.

14. Liberati A, Altman DG, Tetzlaff J, Mulrow C, Gøtzsche PC, loannidis JPA, et al. The PRISMA statement for reporting systematic reviews and meta-analyses of studies that evaluate health care interventions: explanation and elaboration. PLoS Med. 2009;6:e1000100. https://doi.org/10.1371/journal. pmed. 1000100 .

15. National Heart Lung and Blood Institute. Quality Assessment Tool for Observational Cohort and Cross-Sectional Studies; NIH. Available from: https://www.nhlbi.nih.gov/health-topics/study-quality-assessment-tools. Accessed 10 May 2020.

16. Hardy RJ, Thompson SG. A likelihood approach to meta-analysis with random effects. Stat Med. 1996;15:619-29.
17. Higgins JPT, Thompson SG. Quantifying heterogeneity in a meta-analysis. Stat Med. 2002:21:1539-58. https://doi.org/10.1002/sim.1186.

18. Egger M, Davey Smith G, Schneider M, Minder C. Bias in meta-analysis detected by a simple, graphical test. BMJ. 1997;315:629-34. https://doi.org/ 10.1136/bmj.315.7109.629 pmid:9310563.

19. Alfonso-Rosa RM, García-Hermoso A, Sanders T, Parker P, Oriol-Granado X, Arnott H, del Pozo Cruz B. Lifestyle behaviors predict adolescents bullying victimization in low and middle-income countries. J Affect Disord. 2020;273: 364-74. https://doi.org/10.1016/j.jad.2020.04.065.

20. Busch V, Manders LA, De Leeuw JRJ. Screen time associated with health behaviors and outcomes in adolescents. Am J Health Behav. 2013;37:819-30.

21. Case KR, Pérez A, Saxton DL, Hoelscher DM, Springer AE. Bullied status and physical activity in Texas adolescents. Heal Educ Behav. 2015;43:313-20.

22. Corral-Pernía JA, Chacón-Borrego F, Fernández-Gavira J, Del Rey R. Bullying and Cyberbullying according to moderate vigorous physical activity (MVPA) in secondary School's students. Rev de Psicol del Deporte. 2018;27:70-5.

23. Demissie Z, Lowry R, Eaton DK, Hertz MF, Lee SM. Associations of school violence with physical activity among US high school students. J Phys Act Health. 2014;11(4):705-11. https://doi.org/10.1123/jpah.2012-0191.

24. Henriksen PW, Rayce SB, Melkevik O, Due P, Holstein BE. Social background, bullying, and physical inactivity: national study of 11- to 15-year-olds. Scand J Med Sci Sports. 2016;26:1249-55. https://doi.org/10.1111/sms.12574.

25. Herazo-Beltrán Y, Campo-Ternera L, García-Puello F, Méndez O, Suarez-Villa M, Vásquez-De La Hoz F, et al. Relationship between physical activity and emotional intelligence and bullying among school children. Rev Psicol del Deport Sport Psychol. 2019;28:97-104.

26. Hertz MF, Everett Jones S, Barrios L, David-Ferdon C, Holt M. Association between bullying victimization and health risk behaviors among high school students in the United States. J Sch Health. 2015;85:833-42.

27. Katapally TR, Thorisdottir AS, Laxer R, Leatherdale ST. Association entre le sentiment d'appartenance à l'école, la participation à l'intimidation et divers comportements associés au temps passé devant un écran chez les jeunes dans deux provinces canadiennes : Une étude COMPASS. Heal Promot chronic Dis Prev Can Res policy Pract. 2018;38:368-79.

28. Kelishadi R, Qorbani M, Motlagh ME, Heshmat R, Ardalan G, Jari M. Paediatrics and international child health relationship between leisure time screen activity and aggressive and violent behaviour in Iranian children and adolescents: the CASPIAN-IV study relationship between leisure time screen activity and aggressive and violent behaviour in Iranian children and adolescents: the CASPIAN-IV study. Paediatr Int Child Health. 2015;35:30511. https://doi.org/10.1080/20469047.2015.1109221.

29. Méndez I, Ruiz-Esteban C, Ortega E. Impact of the physical activity on bullying. Front Psychol. 2019;10:1520. https://doi.org/10.3389/fpsyg.2019. 01520.

30. Merrill RM, Hanson CL. Risk and protective factors associated with being bullied on school property compared with cyberbullied. BMC Public Health. 2016;16:145. https://doi.org/10.1186/s12889-016-2833-3.

31. Rech RR, Halpern R, Tedesco A, Santos DF. Prevalence and characteristics of victims and perpetrators of bullying. J Pediatr. 2013;89:164-70.

32. Roman CG, Taylor CJ. A multilevel assessment of school climate, bullying victimization, and physical activity. J Sch Health. 2013:83:400-7.

33. Rostad WL, Basile KC, Clayton HB. Association among television and computer/video game use, victimization, and suicide risk among U.S. high school students. J Interpers Violence. 2018. https://doi.org/10.1177/ 0886260518760020

34. Sampasa-Kanyinga H, Colman I, Goldfield GS, Janssend I, Wanga J, Hamiltonf HA, Chaput JP. Associations between the Canadian $24 \mathrm{~h}$ movement guidelines and different types of bullying involvement among adolescents. Child Abuse Negl. 2020;108:104638. https://doi.org/10.1016/j. chiabu.2020.104638.

35. Storch EA, Milsom VA, Debraganza N, Lewin AB, Geffken GR, Silverstein JH. Peer victimization, psychosocial adjustment, and physical activity in overweight and at-risk-for-overweight youth. J Pediatr Psychol. 2007;32(1): $80-9$

36. Watanabe P, Fontana F, da Silva MP, Mazzardo O, Bacil EDA, de Campos W. Association between weight-teasing and physical activity in adolescents. Rev Paul Pediatr. 2017;35(3):309-15.

37. Dangour AD, Albala C, Allen E, Grundy E, Walker DG, Aedo C, et al. Effect of a nutrition supplement and physical activity program on pneumonia and walking capacity in Chilean older people: a factorial cluster randomized trial. PLoS Med. 2011;8:e1001023. https://doi.org/10.1371/journal.pmed.1001023. 
38. Stanley RM, Boshoff K, Dollman J. A qualitative exploration of the "critical window": factors affecting australian children's after-school physical activity. J Phys Act Health. 2013;10:33-41.

39. Hormazábal-Aguayo I, Fernández-Vergara O, González-Calderón N, VicencioRojas F, Russell-Guzmán J, Chacana-Cañas C, Del Pozo-Cruz B, GarcíaHermoso A. Can a before-school physical activity program decrease bullying victimization in disadvantaged children? The active-start study. Int J Clin Heal Psychol. 2019;19:237-42.

40. Frey KS, Hirschstein MK, Snell JL, Van Schoiack EL, MacKenzie EP, Broderick CJ. Reducing playground bullying and supporting beliefs: an experimental trial of the steps to respect program. Dev Psychol. 2005;41:479-90.

41. Gage JC, Overpeck MD, Nansel TR, Kogan MD. Peer activity in the evenings and participation in aggressive and problem behaviors. J Adolesc Heal. 2005;37:517.e7-517.e14.

42. Barnett LM, van Beurden E, Morgan PJ, Brooks LO, Beard JR. Childhood motor skill proficiency as a predictor of adolescent physical activity. J Adolesc Health. 2009:44:252-9.

43. Garcia-Hermoso A, Oriol-Granado X, Correa-Bautista JE, Ramírez-Vélez R. Association between bullying victimization and physical fitness among children and adolescents. Int J Clin Heal Psychol. 2019;19:134-40. https://doi.org/10.1016/j.jichp.2019.02.006.

44. Biddle SJH, Gorely T, Marshall SJ, Cameron N. The prevalence of sedentary behavior and physical activity in leisure time: a study of Scottish adolescents using ecological momentary assessment. Prev Med (Baltim). 2009;48:151-5

45. Rodriquez-Ayllon M, Cadenas-Sánchez C, Estévez-López F, Muñoz NE, MoraGonzalez J, Migueles JH, et al. Role of physical activity and sedentary behavior in the mental health of preschoolers, children and adolescents: a systematic review and meta-analysis. Sports Med. 2019;49:1383-410.

46. Landhuis CE, Perry DK, Hancox RJ. Association between childhood and adolescent television viewing and unemployment in adulthood. Prev Med (Baltim). 2012;54:168-73.

47. Fox CL, Boulton MJ. Friendship as a moderator of the relationship between social skills problems and peer victimisation. Aggress Behav. 2006;32:110-21.

48. Bauer KW, Yang YW, Austin SB. "How can we stay healthy when you're throwing all of this in front of us?" Findings from focus groups and interviews in middle schools on environmental influences on nutrition and physical activity. Heal Educ Behav. 2004;31:34-46. https://doi.org/10.1177/ 1090198103255372.

49. Barkley JE, Salvy SJ, Roemmich JN. The effect of simulated ostracism on physical activity behavior in children. Pediatrics. 2012;129:e659-66. https://doi.org/10.1542/peds.2011-0496.

\section{Publisher's Note}

Springer Nature remains neutral with regard to jurisdictional claims in published maps and institutional affiliations.

Ready to submit your research? Choose BMC and benefit from:

- fast, convenient online submission

- thorough peer review by experienced researchers in your field

- rapid publication on acceptance

- support for research data, including large and complex data types

- gold Open Access which fosters wider collaboration and increased citations

- maximum visibility for your research: over $100 \mathrm{M}$ website views per year

At $\mathrm{BMC}$, research is always in progress.

Learn more biomedcentral.com/submissions 